\title{
Tumor desmoplásico de células redondas y pequeñas: presentación de un caso
}

\author{
Desmoplastic tumor of round and small cells: a case report \\ Tumor desmoplásico de pequenas células redondas: relato de caso
}

\author{
Enrique Ortiz Quevedo (iD a, María Lourdes Nuques Martínez b
}

\begin{abstract}
a Servicio de Cirugía Oncológica, Clínica Guayaquil, GuayaquilEcuador; ' Servicio de Anatomía Patológica, Hospital Luis Vernaza, Guayaquil-Ecuador.
\end{abstract}

\section{Correspondencia a:} Enrique Ortiz Quevedo, xeortiz@hotmail.com

Recibido: 15 de octubre, 2020 Aceptado: 17 de noviembre, 2020 Publicado: 4 de enero, 2021

\section{CASO CLÍNICO}

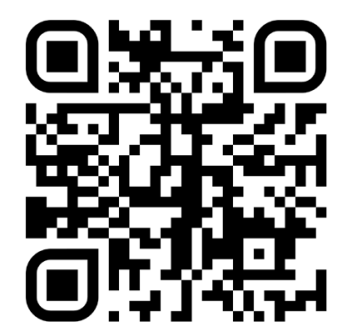

Escanea en tu dispositivo móvil o revisa este artículo en: https:// revistaclinicaguayaquil.org

\section{RESUMEN}

El tumor desmoplásico de células redondas y pequeñas es una neoplasia maligna infrecuente que se presenta más comúnmente en adolescentes y adultos jóvenes. Se localiza generalmente en la cavidad abdominal y en la pelvis, aunque se ha descrito en otras localizaciones. Su histogénesis es incierta y las características histopatológicas relevantes incluyen células pequeñas con núcleos redondeados y escaso citoplasma que se disponen en grupos inmersos en un estroma desmoplásico. El perfil inmunohistoquímico demuestra positividad para marcadores epiteliales, mesenquimales, miogénicos y neuroectodérmicos. Se trata de tumores agresivos con poca respuesta al tratamiento. Se presenta el caso de un hombre de 36 años que consulta por distensión y dolor abdominal. Los estudios radiológicos mostraron una masa voluminosa ubicada en el hipocondrio izquierdo acompañada de tumores de menor tamaño en la cavidad peritoneal y ascitis. El examen anatomopatológico reporta el diagnóstico de tumor desmoplásico de células redondas y pequeñas; los estudios de inmunohistoquímica demuestran el carácter multifenotípico de la lesión. El paciente recibe tratamiento quirúrgico y quimioterapia, a pesar de la terapéutica, el paciente fallece a los 10 meses.

Palabras clave: Tumor desmoplásico de células pequeñas redondas; neoplasia; neoplasias gastrointestinales

\begin{abstract}
The desmoplastic small round cell tumor is an infrequent malignant neoplasm that occurs most commonly in adolescents and young adults. It is generally located in the abdominal cavity and in the pelvis, although it has been described in other locations. Its histogenesis is uncertain; relevant histopathologic features include small cells with rounded nuclei and sparse cytoplasm that are arranged in clusters embedded in a desmoplastic stroma. The immunohistochemical profile shows positivity for epithelial, mesenchymal, myogenic and neuroectodermal markers. These tumors are aggressive and have little response to treatment. We present the case of a 36-year-old man who consulted for abdominal distention and pain. Radiological studies showed a voluminous mass located in the left upper quadrant accompanied by smaller tumors in the peritoneal cavity and ascites. The anatomopathological examination reported a desmoplastic small round cell tumor; immunohistochemical studies demonstrated the multiphenotypic character of the lesion. The patient had surgical treatment and chemotherapy, despite the therapy, the patient died after 10 months.
\end{abstract}

Key words: Desmoplastic small round cell tumor; neoplasm; gastrointestinal neoplasm 


\section{RESUMO}

O tumor desmoplásico de pequenas células redondas é uma neoplasia rara que ocorre mais comumente em adolescentes e adultos jovens. Geralmente está localizado na cavidade abdominal e na pelve, embora tenha sido descrito em outras localizações. Sua histogênese é incerta e as características histopatológicas relevantes incluem pequenas células com núcleos arredondados e citoplasma escasso que são organizados em grupos imersos em um estroma desmoplásico. O perfil imunohistoquímico mostra positividade para marcadores epiteliais, mesenquimais, miogênicos e neuroectodérmicos. São tumores agressivos com pouca resposta ao tratamento. Apresentamos o caso de um homem de 36 anos que consultou por inchaço e dor abdominal. Os estudos radiológicos mostraram uma volumosa massa localizada no quadrante superior esquerdo acompanhada por tumores menores na cavidade peritoneal e ascite. O exame anatomopatológico relata o diagnóstico de tumor desmoplásico de pequenas células redondas; Estudos imunohistoquímicos demonstram o caráter multifenotípico da lesão. O paciente recebe tratamento cirúrgico e quimioterapia, apesar da terapia, o paciente morre após 10 meses.

Palavras-chave: Tumor desmoplásico de pequenas células redondas; neoplasias; neoplasias gastrointestinais

\section{INTRODUCCIÓN}

El tumor desmoplásico de células pequeñas y redondas es una neoplasia poco frecuente que afecta generalmente a la serosa de los órganos intraabdominales sin un origen visceral aparente. Puede presentarse como una masa única o como múltiples tumores dentro de la cavidad abdominal, aunque se ha descrito también en otras localizaciones; afecta principalmente a personas en la segunda y tercera década de la vida y es más frecuente en hombres $(1,2)$.

Se presenta el caso de un paciente que consulta por distensión y dolor abdominal. Los estudios radiológicos mostraron una masa voluminosa ubicada en el hipocondrio izquierdo acompañada de tumores de menor tamaño en la cavidad peritoneal y ascitis.

\section{DESCRIPCIÓN DEL CASO CLÍNICO}

Paciente masculino de 36 años, sin antecedentes patológicos de importancia, acude a consulta por presentar dolor y distensión abdominal acompañado de disnea de decúbito y pérdida de peso, aproximadamente $15 \mathrm{~kg}$, de seis meses de evolución. Al examen físico presentó ictericia y una masa en hipocondrio izquierdo, seis centímetros por debajo del reborde costal que se extiende de manera irregular hasta hipocondrio derecho.

Previamente, el paciente se había realizado una biopsia por punción que reportó únicamente tejido necrótico, así como una tomografía computarizada de tórax y abdomen donde se evidenció una masa a nivel de hipocondrio izquierdo multilobulada que comprime estómago, desplaza bazo y se extiende hasta hipocondrio derecho comprimiendo la vía biliar; se reportan, además, varios tumores intraabdominales y ascitis. El paciente había sido atendido previamente en otra institución donde le colocaron un stent en vías biliares.

Se decide realizar laparotomía exploradora encontrando una masa que comprime estómago y desplaza al hígado, acompañada de varios tumores multilobulados ubicados en hipocondrio derecho y epiplón mayor. Se realizó tumorectomía. La muestra enviada a anatomía patológica describió un tumor ovalado, parcialmente delimitado que mide $21 \times 15 \times 10 \mathrm{~cm}$, que muestra adherido a su superficie externa un segmento de epiplón que mide $30 \times 25 \times 0.2$ $\mathrm{cm}$; al corte, el tumor presenta una superficie de color gris blanquecino, de consistencia firme, de aspecto fibroso; se reciben también tres tumores de menor tamaño, cuyos diámetros fluctúan entre 1.5 y $4.5 \mathrm{~cm}$ con las mismas características macroscópicas del tumor de mayor tamaño. El reporte microscópico describe que los tumores se hallan constituidos por células pequeñas con núcleos redondeados que se disponen en nidos inmersos en abundante estroma desmoplásico, se observan mitosis en moderada cantidad, áreas de hemorragia y necrosis; se realizaron técnicas de inmunohistoquímica: Desmina $(+)$, Vimentina (+), CD45 (-), CKAE1-AE3 (+), WT1 (+), Ki-67(+) 40\% (Figuras 1 y 2). También se analizó el líquido ascítico. El diagnóstico histopatológico fue tumor desmoplásico de células redondas y pequeñas intraabdominal y el líquido ascítico positivo para células malignas. 

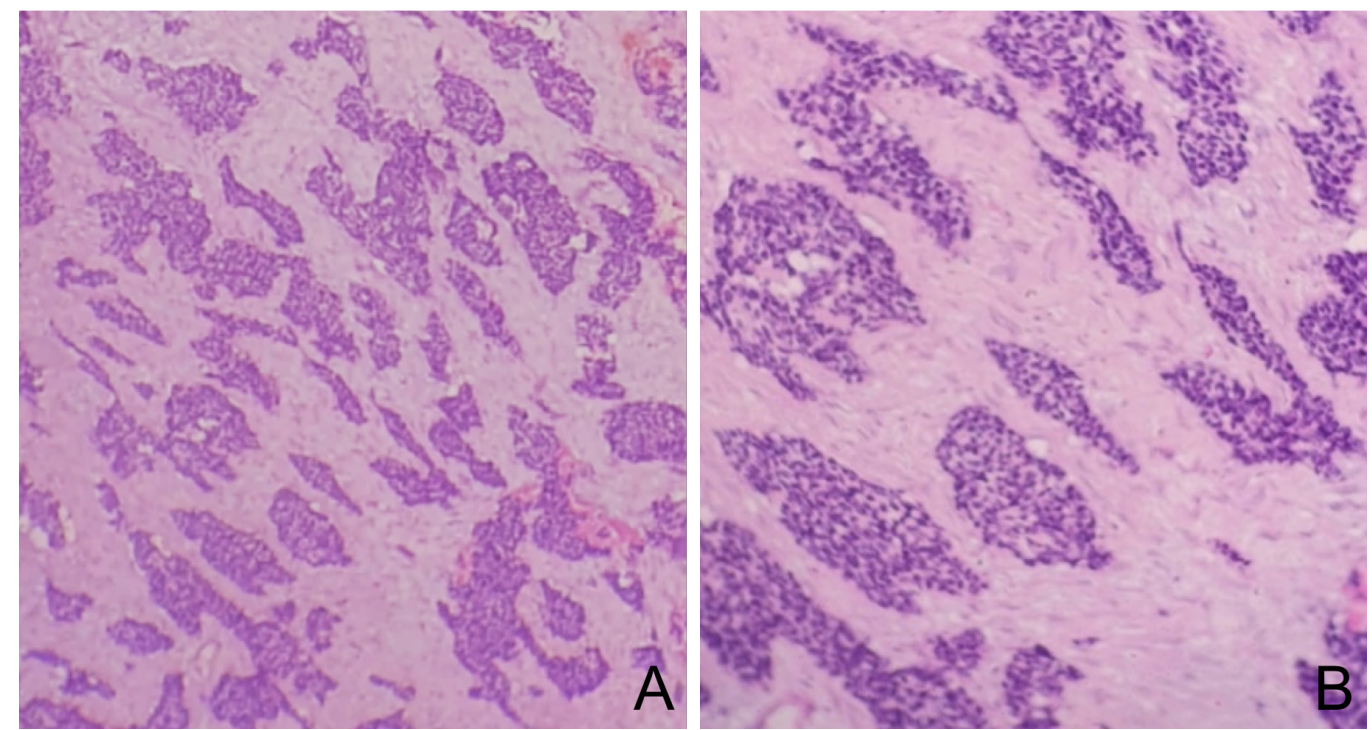

Figura 1. Tinción de Hematoxilina \& Eosina: Tumor desmoplásico de células redondas y pequeñas. Se observan nidos de células pequeñas con núcleos redondeados inmersos en abundante estroma desmoplásico (A y B).
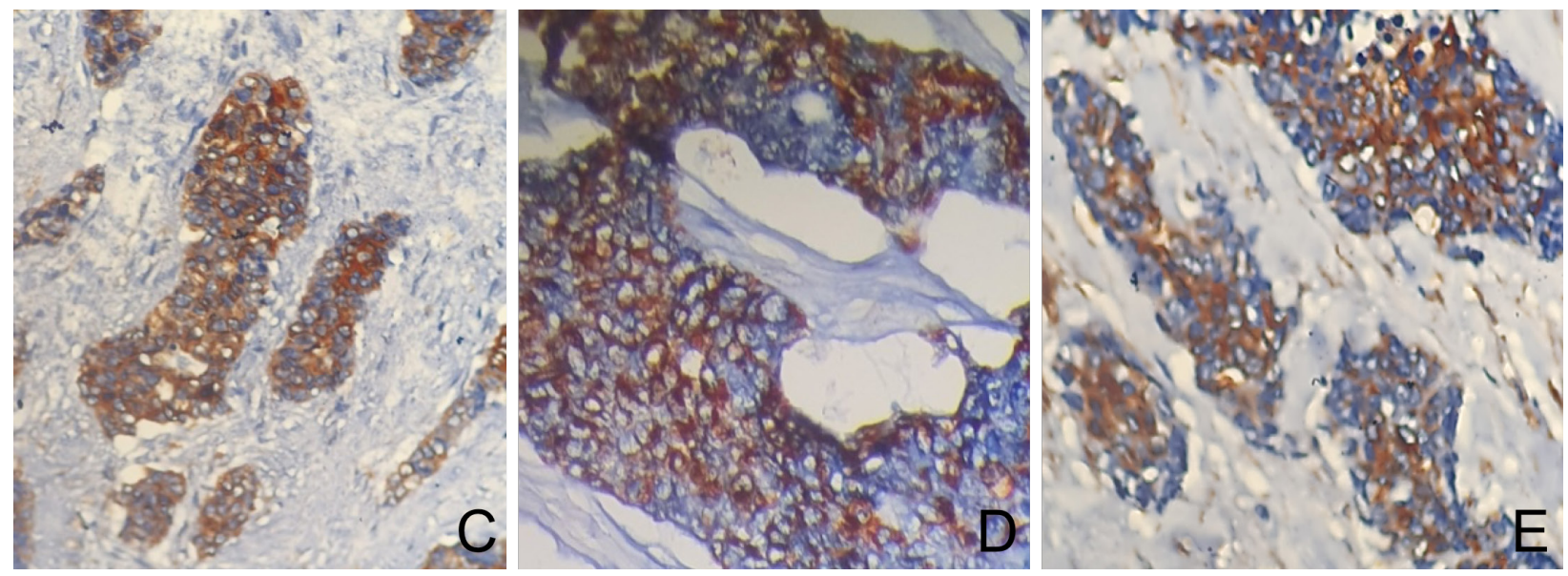

Figura 2. Inmunohistoquímica: Tumor desmoplásico de células redondas y pequeñas. Se evidencian nidos de células pequeñas con núcleos redondeados inmersos en abundante estroma desmoplásico: Citoqueratina AE1 - AE3 (C); Desmina (D); y Vimentina (E).

Luego de la cirugía se inicia tratamiento de quimioterapia, no obteniendo resultados favorables. El paciente fallece diez meses después debido a progresión de la enfermedad.

\section{DISCUSIÓN}

El tumor desmoplásico de células pequeñas y redondas es una neoplasia poco frecuente, reportándose pocos casos a nivel mundial. Fue descrito por primera vez por Gerarld y Rosai en 1989 (3). Es más frecuente en varones que en mujeres, mostrando una proporción de 4:1, y tiene una mayor incidencia durante la segunda y tercera década de la vida (4). El sitio de localización más frecuente es la superficie serosa de órganos intraabdominales, no teniendo un origen visceral claro, y la presentación suele ser como una masa de tamaño variable acompañada de varios tumores peritoneales de menor tamaño, que en ocasiones pueden involucrar el retroperitoneo. Otros sitios donde se ha descrito la presencia de este tumor incluyen pleura, pelvis (simulando tumores ováricos primarios), región paratesticular, tejidos blandos, fosa craneal posterior, glándula parótida, y hueso. Es frecuente la presencia de ascitis, identificándose células neoplásicas en el estudio citológico del fluido $(1,2)$.

Su histogénesis no es clara; debido a la ubicación se ha propuesto su origen en células primitivas de origen mesotelial, sin embargo, su presencia en otros lugares que no tienen 
superficies serosas pone en duda esta hipótesis. Se ha demostrado la translocación entre el gen de Sarcoma de Ewing y el gen WT1 del tumor de Wilms $t(11,22)(p 13, q 12)$, también se han descrito otras translocaciones cromosómicas asociadas (3,5-7).

Los signos y síntomas más frecuentes son aquellos relacionados con un tumor intraabdominal (distensión, dolor, masa palpable), lo cual concuerda con los datos del paciente presentado. También pueden estar presentes síntomas relacionados con obstrucción intestinal como náuseas, vómitos o constipación. Otros síntomas descritos son dolor de espalda, dolor de pecho, disnea, principalmente si hay compromiso pleural o debido a ocupación de la cavidad abdominal por el tumor o ascitis. La afectación de la vejiga o uréteres puede producir hematuria, disuria, polaquiuria (4).

Las características histomorfológicas muestran que la neoplasia está constituida por células pequeñas con núcleos redondeados, hipercromáticos y escaso citoplasma que se disponen en nidos o trabéculas rodeados de estroma desmoplásico. Generalmente, los núcleos son uniformes y pequeños, aunque pueden observarse zonas con diferentes grados de atipia nuclear. Los nidos de células pueden mostrar zonas de necrosis central $(1,2,6,8)$. Se piensa que el estroma desmoplásico es producto de la activación del factor de crecimiento alfa derivado de plaquetas que promueve la proliferación fibroblástica (7).

De acuerdo a su morfología, el tumor desmoplásico de células redondas y pequeñas corresponde al grupo de neoplasias conocido como tumores de células redondas y pequeñas. Estos son neoplasias incluyen al sarcoma de Ewing/PNET, linfomas no Hodgkin, rabdomiosarcoma alveolar, neuroblastoma, nefroblastoma (Tumor de Wilms) $(9,10)$. La evaluación de parámetros como la historia clínica, distribución anatómica de las lesiones, características histopatológicas, así como, el perfil de inmunohistoquímica que demuestra la diferenciación multifenotípica del tumor (positividad para marcadores epiteliales como la citoqueratinayEMA, marcadoresmesenquimales y miogénicos como vimentina, desmina, miogenina, y marcadores neuroectodérmicos como la enolasa neuroespecífica), acompañados de la evidencia de alteraciones genéticas, permiten hacer un diagnóstico diferencial con respecto a las otras neoplasias que forman parte de la familia de los tumores de células redondas y pequeñas $(5,8,10)$. El diagnóstico diferencial con respecto a carcinoma de células pequeñas y mesotelioma de células pequeñas también se basa en los parámetros anotados anteriormente.

El tumor desmoplásico de células pequeñas y redondas es un tumor agresivo que, cuando se encuentra en ubicación intraabdominal, generalmente afecta la serosa de los órganos o el peritoneo, en ocasiones produciendo compresión extrínseca de las vísceras. Sin embargo, se ha descrito el compromiso del parénquima de órganos como el hígado, páncreas, y ovario. Las metástasis a ganglios linfáticos son raras, pero se han encontrado en estadios avanzados de la enfermedad, así como metástasis hematógenas que principalmente comprometen al hígado. El pronóstico es malo, con una escasa respuesta a la quimioterapia $(2,8,9)$.

\section{REFERENCIAS BIBLIOGRÁFICAS}

1. Weiss SW, Goldblum JR. Tumores de partes blandas. 5ta ed. Barcelona: Elsevier; 2009. 1268 p.

2. Rosai J. Rosai y Ackerman. Patología Quirúrgica. 10a ed. Amolca; 2013. 2940 p.

3. Markinez Gordobil I, Ruiz I, Jiménez R, Villarreal E, Lizarazu A, Borda N, y col. Tumor desmoplásico de céulas pequeñas y redondas. Diagnóstico y tratamiento. Gac Med Bilbao [Internet]. 2012;109(3):101-3. Disponible en: http:// www.gacetamedicabilbao.eus/index.php/ gacetamedicabilbao/article/view/150/0

4. Kempson RL, Fletcher CD, Evans HL, Hendrickson MR, Sibley RK. Atlas of tumor pathology. Tumors of the soft tissues. Third series. Fascicle 30. Washington DC: Armed Forces Institute of Pathology; 2003.

5. Briseño-Hernández AA, Quezada-López DR, Corona-Cobián LE, Castañeda-Chávez A, Duarte-Ojeda AT, Macías-Amezcua MD. Tumor intraabdominal desmoplásico de células pequeñas y redondas. Cir Cir [Internet]. 2015;83(3):243-8. Disponible en: https://www.sciencedirect.com/ science/article/pii/S0009741115000675

6. Cabrera Morales CM. Tumor desmoplásico de células pequeñas y redondas (DSRCT) de riñón. Oncol. 2005;28:38-42.

7. Tejerina González E, Corbacho Cuevas C, López García A, Bellas Menéndez C, Sánchez Turrión V, Sánchez Ruiz A, y col. Tumor intraabdominal desmoplásico de células pequeñas y redondas: Revisión de la literatura a propósito de un caso con estudio citológico, histopatológico, inmunohistoquímico y molecular. Oncol. 2007;30:35-41. 
8. Dufresne A, Cassier P, Couraud L, Marec-Bérard P, Meeus P, Alberti L, et al. Desmoplastic Small Round Cell Tumor: Current Management and Recent Findings. Sarcoma [Internet]. 2012;2012:1-5. Disponible en: https://doi. org/10.1155/2012/714986

9. Bellah R, Suzuki-Bordalo L, Brecher E, Ginsberg JP, Maris J, Pawel BR. Desmoplastic small round cell tumor in the abdomen and pelvis: report of CT findings in 11 affected children and young adults. Am J Roentgenol. 2005;184(6):1910-4.

10. Paz-Gómez F. Tumor de células pequeñas, redondas y azules: abordaje diagnóstico. Med Sur [Internet]. 2004;11(1):13-9. Disponible en: http:// www.medigraphic.com/pdfs/medsur/ms-2004/ ms041c.pdf

\section{ACERCA DE LOS AUTORES}

1. Enrique Ortiz Quevedo. Servicio de Cirugía General y Oncológica, Clínica Guayaquil, Guayaquil-Ecuador.

ORCID: 0000-0003-3657-5132

2. María Lourdes Nuques Martínez. Departamento de Anatomía Patológica, Hospital Luis Vernaza, Ecuador. 